\title{
Impact of Low and High Congestion Traffic Patterns on a Mild-HEV Performance
}

\author{
Author, co-author (Do NOT enter this information. It will be pulled from participant tab in \\ MyTechZone) \\ Affiliation (Do NOT enter this information. It will be pulled from participant tab in MyTechZone)
}

\begin{abstract}
Driven by stricter mandatory regulations on fuel economy improvement and emissions reduction, market penetration of electrified vehicles will increase in the next ten years. Within this growth, mild hybrid vehicles will become a leading sector. The high cost of hybrid electric vehicles (HEV) has somewhat limited their widespread adoption, especially in developing countries. Conversely, it is these countries that would benefit most from the environmental benefits of HEV technology. Compared to a full hybrid, plug-in hybrid, or electric vehicle, a mild hybrid system stands out due to its maximum benefit/cost ratio. As part of our ongoing project to develop a mild hybrid system for developing markets, we have previously investigated improvements in drive performance and efficiency using optimal gearshift strategies, as well as the incorporation of high power density supercapacitors. In this paper, the fuel and emissions of a baseline conventional vehicle and mild hybrid electric vehicle (MHEV) are compared. The objective of this analysis is to compare the fuel economy and Greenhouse Gas (GHG) emissions of the baseline and MHEV models, using low and highdensity traffic patterns chosen for their similarity to traffic density profiles of our target markets. Results demonstrate the benefits of a lower ongoing cost for the HEV architecture. These advantages include torque-hole filling between gear changes, increased fuel efficiency and performance.
\end{abstract}

\section{Introduction}

For conventional vehicles equipped with manual transmission (MT) transmissions, a characteristic of the gear selection process is the introduction of a sudden change in the engine operating point, due to a stepped shift in the transmission ratio. With highly non-linear characteristics for fuel consumption (FC) and maximum torque of the internal combustion (IC) engine, a change in the engine operating point due to a gear shift can result in fuel-inefficient operation states and/or poor-drivability conditions. Either of these has the effect of increasing greenhouse gas (GHG) emissions. Typically, these drawbacks have been overcome using more complex or less fuelefficient transmission technologies. These technologies include the automatic transmission (AT), dual-clutch transmission (DCT), automated manual transmission (AMT) and continuously variable transmission (CVT). However, compared to an MT each of these technologies is generally more expensive, and/or causes increased fuel consumption. Overcoming these drawbacks whilst retaining the MT's cost advantage is therefore essential to successfully designing a hybrid vehicle for developing markets.
Modern hybrid powertrains aim to deliver excellent ride quality and high efficiency through smooth tractive torque delivery with improved fuel economy and emissions [1], [2]. To this end, some powertrains employ complex power shifting capable transmissions, minimising shift transients, but introducing other limitations and increasing cost [3]. The mild hybrid structure used in this paper employs a low voltage electric motor coupled to the output shaft of a manual transmission. To overcome the gear selection characteristics of the MT, the electric machine is used primarily to provide a torquefill function during gear change events. The motor is selected such that it is also powerful enough to be employed in a secondary function as a supplemental torque source to gain observable improvements in vehicle efficiency, both under high demand or low ICE efficiency conditions [4]. The manual transmission provides the most economical system for manufacture with increased power transfer efficiency [5]. In the context of the mild hybrid vehicle described, the disadvantages of an MT may be remedied. Owing to the low-cost of the MT, with suitable system design there is potential for the implementation of a mild hybrid electric powertrain employed with a manual transmission (MT) to improve driving comfort, shifting quality and drivability with an associated reduction in the cost of manufacture, and consequently a reduced cost for customers. Our aim of reducing the production of air pollution in the transport sector is realised by developing a practical proof-of-concept hybrid vehicle suitable for developing regions. This includes a focus on developing a gear-shift control strategy for such a vehicle [6-8].

A number of recent studies have been conducted into the application of hybridized and electrified power shifting transmission systems. For a conventional vehicle Galvagno [9] designed a power shifting AMT by replacing the synchronizer mechanism on the highest gear ratio with a friction clutch, thus enabling power on up and down shifts for the system. In electric vehicles, Gao [10] designed an inverse AMT for electric vehicles, with the clutch on the low-speed section. Clutchless Automated Manual Transmissions (CAMT) have also been viewed as cost effective transmission systems for electric and hybrid vehicles [11]. Such designs typically increase the torque and speed capabilities of the EV at the cost of overall efficiency in comparison to a single speed EV. Not dissimilar to the powertrain prototype proposed in this paper is a dual motor hybrid vehicle, proposed in [12]. This topology uses a combination of synchronizers, gears and large electric motors upstream of the transmission to achieve similar functions for shift control as described in this research, but with an increased complexity of the system and for its control.

In these simulations, an 8 degree-of-freedom (DOF) vehicle dynamics model was created using Simulink and sits at the core of 
the vehicle simulation. The utilisation of simulation and modelling in developing a Mild Hybrid Electric Vehicle (MHEV) system has been previously discussed and examined in both testing and validating vehicle drive trains with runs in different driving cycles are discussed in earlier papers [13-15]. This paper presents a comparative study on the fuel economy and emissions using different standard drive cycles and different developed low and high-density traffic patterns and real world drive cycles. Elements of the controlled GHG emissions include Carbon Monoxide (CO), Hydro Carbons (HC), Nitrogen Oxides (NOx) and particulate matter (PM).

The vehicle type selected is an average 5-passenger sedan, which is representative of the majority of vehicles on the road. The architecture of the model can be seen in Figure 1, consisting of the engine, flywheel and pressure plate, dry clutch plate, manual transmission gears, shaft, differential, driveshaft, wheels, and vehicle inertia is included. More detailed specific features are shown in Table 1 outlines the vehicle parameters which were used in the model.

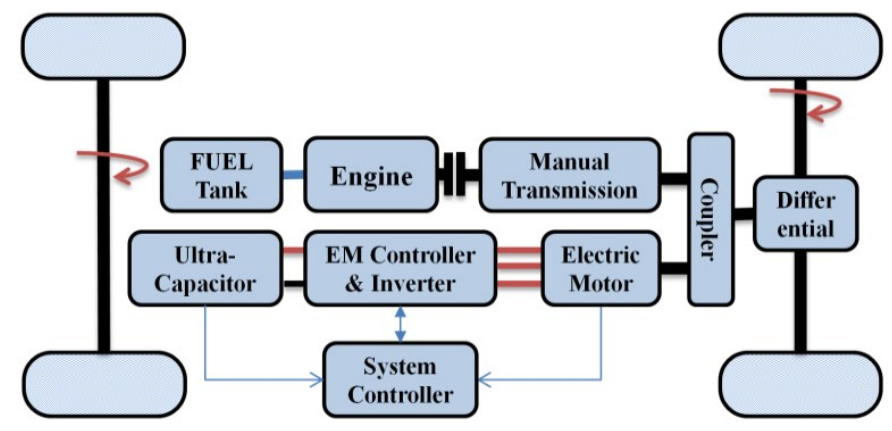

Figure 1. Powertrain Architecture.

Table 1. Vehicle Global Specifications

\begin{tabular}{|c|c|c|}
\hline Component & Parameter & SI Units \\
\hline \multirow{7}{*}{ Vehicle } & Mass as hybrid & $1200 \mathrm{~kg}$ \\
\hline & Frontal area & $3 \mathrm{~m}^{2}$ \\
\hline & Drag coefficient & 0.4 \\
\hline & CG to front axle distance & $1.4 \mathrm{~m}$ \\
\hline & CG to rear axle distance & $1.6 \mathrm{~m}$ \\
\hline & CG height & $0.5 \mathrm{~m}$ \\
\hline & Tire rolling radius & $0.312 \mathrm{~m}$ \\
\hline \multirow{6}{*}{ Engine } & Type & Spark-Ignition \\
\hline & Maximum power & $70 \mathrm{~kW}$ \\
\hline & Speed at maximum power & $5000 \mathrm{rpm}$ \\
\hline & Maximum speed & $7000 \mathrm{rpm}$ \\
\hline & Idling speed & $800 \mathrm{rpm}$ \\
\hline & Cylinders & 4 \\
\hline \multirow{2}{*}{ Clutch } & Type & Single dry clutch \\
\hline & Friction coefficient & 0.3 \\
\hline \multirow{3}{*}{ Gear ratio } & Type & $\begin{array}{l}\text { Manual, } 5 \text { forward } 1 \\
\text { reverse, fully } \\
\text { synchronised }\end{array}$ \\
\hline & First to Fifth & $\begin{array}{l}3.581,2.022,1.4,1.03 \text {, } \\
0.94\end{array}$ \\
\hline & Final drive ratio & 4.06 \\
\hline \multirow{4}{*}{ Motor } & Type & BLDC \\
\hline & Voltage & $96 \mathrm{~V}$ \\
\hline & Maximum power output & $10 \mathrm{~kW}$ \\
\hline & Maximum torque & $54 \mathrm{Nm}$ \\
\hline \multirow{3}{*}{ Supercapacitor } & Number of Cells & 2 \\
\hline & Capacitance, $\mathrm{C}$ & $165 \mathrm{~F}$ \\
\hline & Voltage & $48 \mathrm{~V}$ \\
\hline
\end{tabular}

\section{System with supercapacitor energy storage}

The powertrain includes the mild hybrid components which are the motor, inverter, supervisor control and supercapacitors (also known as ultracapacitors). The motor is coupled to the transmission output shaft and directly drives the wheels through a fixed gear ratio. Such a configuration is typically defined as a post-transmission parallel-type hybrid vehicle powertrain. Most existing hybrid vehicles contain two separate electric machines (EM) functioning as a traction motor and generator, respectively. A new conceptual MHEV is proposed. The MHEV contains only one EM, operated as either an electric motor or generator in different time intervals, controlled by a special controller. The use of supercapacitors (SC), while retaining many beneficial aspects of electrochemical batteries, appear to be an alternative solution. Prior work comparing the implementation of electrochemical batteries and supercapacitors has been published by the authors in [16] In that work, they have shown some potential improvements over batteries. One of the main improvements was improved regenerative braking performance. Supercapacitors have a very high power density, allowing a higher charge rate than is achievable with a battery pack and thus more energy can be recouped during regenerative braking. However, they also have a very low energy density relative to batteries, making them only really suited to the minimal energy storage requirements of MHEV powertrains [17], [18]. Some of the advantages of the implementation of SC include fast charge and discharge time, large capacity, long cycle life and other characteristics. SC can reduce peak battery currents with no chemical variations on the electrodes. This results in a noticeable improvement in the life cycle when compared to batteries. In addition to this comparison, there is an improvement of speed of energy consumption and generation, based on the SC ability to supply power demand in a shorter time. The primary storage is the SC bank, which captures the energy from regenerative braking and to supply peak current for fast acceleration, which cannot easily be handled by the battery. The SC's terminal voltage is also directly proportional to State of Charge (SOC). Other previous papers by the authors [19], [20] have discussed both the development and testing of a small-scale drive system based on supercapacitors as energy storage media.

\section{Simulation Model}

A complete vehicle model, including physical and control components, was developed in the Simscape/Simulink environment. Given the complexity of the model, solvers were implemented and configured to optimise the simulation parameters to achieve sufficient simulation accuracy and speed [21]. The simulation uses the velocity profile of the assigned driving schedule as an input. From this, torque and power demands are generated and distributed by component characteristics and selected operating strategies. The electrical energy storage was parametrized to allow the easy reconfiguration between battery and supercapacitor, the main changes related to a raised regenerative braking threshold before brake blending was required, and the ability to provide greater electric-only assistance under higher torque demands - although for a shorter period due to the lower energy density. The model was implemented using the relevant Simscape toolbox component block. The model is forward-facing (a top-down modelling strategy). The force-generating systems such as tires, powertrain, brakes, suspension, and aerodynamics are taken into account in the model. A PID controller is implemented as the driver, operating the pedals and shifter. The shifter is operated according to a two-dimensional shift schedule. Many typical city driving cycles can be simulated in the 'Driver' unit to yield more realistic simulation results, as discussed in [22]. 
The energy management strategy for the MHEV model is a rulebased strategy based on SOC, described in [16]. The electric motor is employed either as a motor or generator depending on the vehicle operating condition and driver demand, and has four operating programmes: Regenerative braking; EM as a generator; Torque-hole filling, and; Idle mode. Figure 8 is focused on the effects of Regenerative Breaking on the SOC of the battery on the MHEV powertrain during the example of high congestion drive cycle. The battery was charged to a high SOC level; each test is started with a high $90 \%$ SOC. The vehicle was determined low SOC at $68 \%$, was reached. The test is repeated with Regenerative Breaking enabled mode. The SOCs during the example of high congestion drive cycles was reached at $85 \%$.

The regenerative braking mode is triggered when a braking event is commanded by the driver, and brake blending is according to classical braking models [23] Torque-hole filling is triggered using a clutch pressure sensor and controlled using predictive models. All other operating modes are as per Figure 2.

Several standard drive cycles have been considered to evaluate the benefits of the proposed our MHEV powertrain presented in [24]. In this study, the fuel consumption and emissions for each vehicle configuration developed are presented. A discussion of the impact of traffic patterns is based on standard and author-developed traffic patterns and drive cycles. These cycles simulate low and high-density traffic. The Indian urban driving cycle (INDIAN URBAN) and highway fuel economy test (HWFET) were used as the basis for this study. These cycles are illustrated in Figure 3 and Figure 4. The HWFET drive cycle consists of a mild initial acceleration for about $100 \mathrm{sec}$ from zero velocity until the vehicle attains the highway velocity. Once the highway velocity level is reached, the vehicle velocity varies from 70 to $80 \mathrm{~km} / \mathrm{s}$ followed by a steep drop to 45 $\mathrm{km} / \mathrm{s}$ at $300 \mathrm{sec}$ and then a rapid increase to nearly $96 \mathrm{~km} / \mathrm{s}$. The drive cycle ends as the vehicle slows down to zero velocity at $765 \mathrm{sec}$ covering $16.5 \mathrm{~km}$ (10.26 miles) at an average speed of $77.6 \mathrm{~km} / \mathrm{h}$ (48.5 mph). The INDIAN URBAN drive cycle is recorded under typical city driving conditions, and it lasts for $2689 \mathrm{sec}$ covering a distance of $17.4 \mathrm{~km}$ (10.8 miles) with an average speed of $23.3 \mathrm{~km} / \mathrm{h}$ $(14.4 \mathrm{mph})$ and a maximum speed of $62 \mathrm{~km} / \mathrm{s}$. Table 2 shows some characteristic parameters of the selected drive cycles, according to these parameters the cycles can be classified into different driving patterns [25], [26].

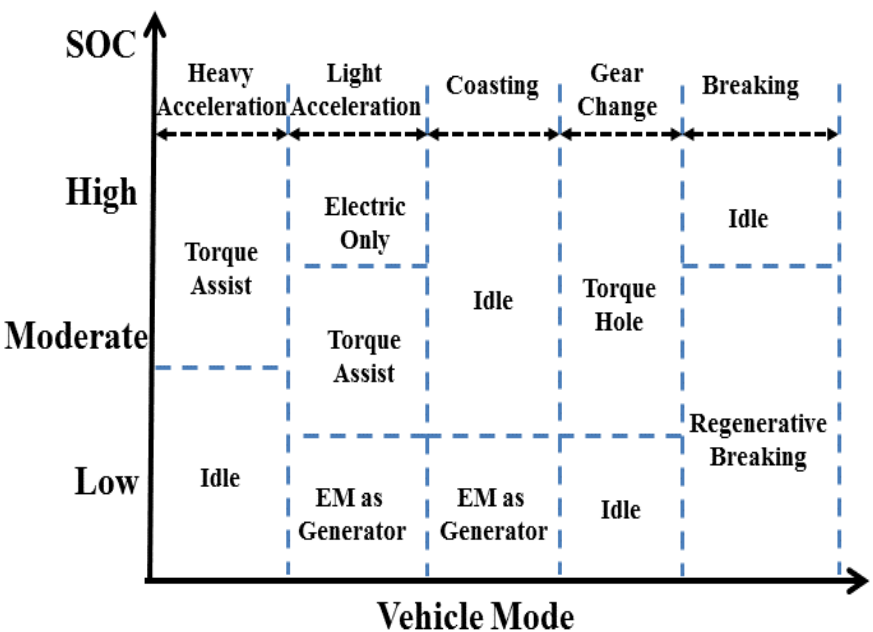

Figure 2. EM modes of operation
Table 2. Characteristic parameters of different driving cycles.

\begin{tabular}{|l|l|l|}
\hline & INDIAN URBAN & HWFET \\
\hline Distance $(\mathrm{km})$ & 17.4 & 16.5 \\
\hline Duration $(\mathrm{Sec})$ & 2689 & 765 \\
\hline Max Speed $(\mathrm{km} / \mathrm{h})$ & 62.2 & 96.4 \\
\hline Average Speed $(\mathrm{km} / \mathrm{h})$ & 23.3 & 77.6 \\
\hline Average Acc $(\mathrm{g})$ & 0.3 & 0.19 \\
\hline Idle Time $(\mathrm{sec})$ & 267 & 6 \\
\hline Number of stops & 52 & 1 \\
\hline
\end{tabular}

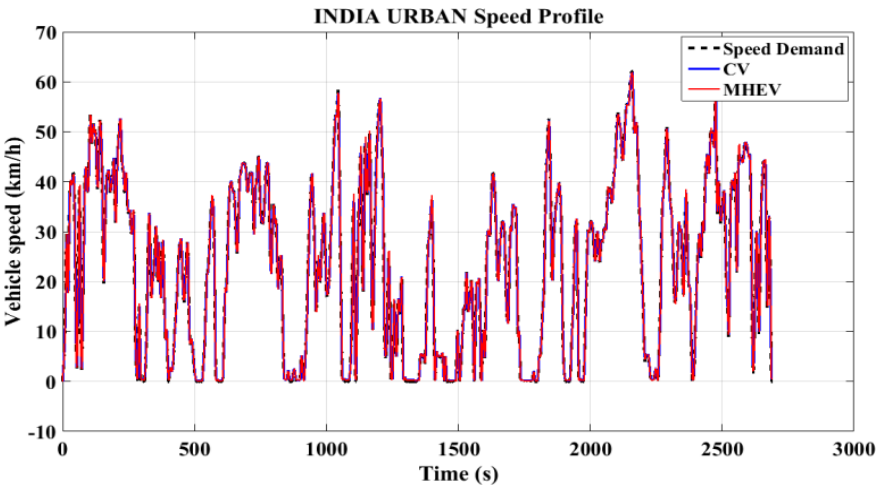

Figure 3. The speed profile of INDIAN URBAN Drive Cycle.

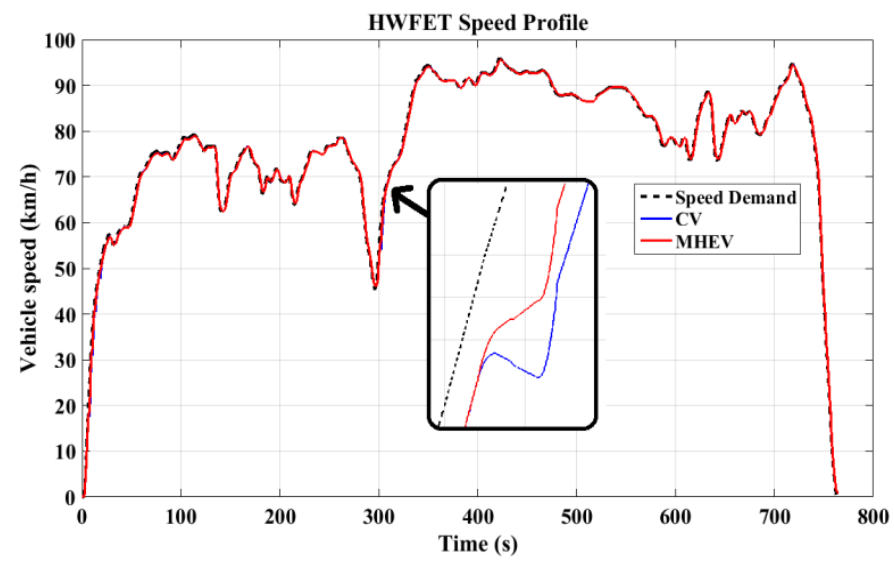

Figure 4. The speed profile of HWFET Drive Cycle.

The fuel economy and emissions for different drive cycles are given in Table 3 and Table 4 . The results shown in these tables demonstrates the equivalent fuel economy of both powertrains varies greatly dependent upon driving environment. As expected, the fuel economy and emissions of the MHEV are better compared to a conventional powertrain. An improvement of approximately $10 \%$ is observed in INDIAN URBAN, and a smaller improvement of $2 \%$ is measured in HWFET. Fuel and emissions indicators improve when the drive cycle is completed using a cautious driving style and with increased "urbanisation" of the cycle. The "stop-start' conditions and high level of speed fluctuation represent the ideal conditions for maximising utilisation factor of the electrified powertrain. This is because the powertrain is particularly adapted to be used in lowpower acceleration at low speed, and as torque-fill during gear changes. So the behaviour of traffic flow proves to be a major contributor influencing fuel consumption in urban regions. The result of this is enhanced fuel economy with mild hybrid configuration implementation, with a significantly smaller improvement in highway cycles than city driving. 
Table 3. Fuel economy and emissions for INDIAN URBAN drive cycle.

\begin{tabular}{|c|c|c|c|c|c|}
\hline & \multicolumn{5}{|c|}{ INDIAN URBAN } \\
\hline & \multicolumn{2}{|c|}{ Fuel } & \multicolumn{3}{|c|}{$\begin{array}{l}\text { Emissions } \\
\text { (grams/km) }\end{array}$} \\
\hline & $\begin{array}{l}\text { Fuel Consumption } \\
\text { (L) }\end{array}$ & $\begin{array}{l}\text { Fuel Economy } \\
(\mathrm{L} / 100 \mathrm{~km})\end{array}$ & $\mathrm{HC}$ & $\mathrm{CO}$ & NOx \\
\hline $\mathrm{CV}$ & 1.9 & 11.1 & 0.45 & 1.9 & 0.69 \\
\hline MHEV & 1.7 & 10 & 0.42 & 1.2 & 0.57 \\
\hline
\end{tabular}

Table 4. Fuel economy and emissions for HWFET drive cycle.

\begin{tabular}{|c|c|c|c|c|c|}
\hline & \multicolumn{5}{|c|}{ HWFET } \\
\hline & \multicolumn{2}{|c|}{ Fuel } & \multicolumn{3}{|c|}{$\begin{array}{c}\text { Emissions } \\
\text { (grams/km) }\end{array}$} \\
\hline & $\begin{array}{l}\text { Fuel Consumption } \\
\text { (L) }\end{array}$ & $\begin{array}{l}\text { Fuel Economy } \\
(\mathrm{L} / 100 \mathrm{~km})\end{array}$ & $\mathrm{HC}$ & $\mathrm{CO}$ & NOx \\
\hline $\mathrm{CV}$ & 0.95 & 5.8 & 0.43 & 1.59 & 0.62 \\
\hline MHEV & 0.93 & 5.7 & 0.41 & 1.43 & 0.57 \\
\hline
\end{tabular}

The combined drive cycle is determined by weighting the city at $55 \%$ and the highway at $45 \%$ as the following equation [27]. Results are outlined in Table 5. The fuel economy for the combined drive cycle is $6 \%$ better than can be achieved by the conventional vehicle $(\mathrm{CV})$.

$$
F E_{\text {combined }}=\frac{1}{\frac{0.55}{F E_{\text {city }}}+\frac{0.45}{F E_{\text {highway }}}}
$$

Table 5. Fuel economy and emissions comparison for the composite drive cycles.

\begin{tabular}{|l|l|}
\hline \multicolumn{2}{|c|}{ COMPOSITE DRIVE CYCLE FUEL ECONOMY (L/100 km) } \\
\hline CV & 7.9 \\
\hline MHEV & 7.4 \\
\hline
\end{tabular}

\section{Low and high-density traffic patterns drive cycles}

There is an identified need for new drive cycles and combination cycles other than those that are used today, due to changes in traffic conditions and infrastructure. Drive cycles can vary considerably from drivers' real-world experiences. As areas become more densely populated and developed, a drive cycle developed for a specific application is not routinely updated, and as a result drive cycles lose relevance over time. This issue is particularly clear outside the USA and Europe, where more regional drive cycles may not be updated for decades. Some efforts have been made to create uniform worldwide regulation. These efforts often constitute smaller regions adopting US or European emissions regulations. However, conversely to the intended outcome, this harmonization can result in adverse emissions outcomes, as the drive cycles that form the basis of emissions legislation are not representative of typical local driving patterns. To combat this, a world-harmonized light vehicle test procedure has been developed, and moves toward "real world" testing utilizing portable emissions measurement systems (PEMS) are in advanced stages. In the absence of significant real-world data and analysis protocols, drive cycles still represent the most practical means of modelling emissions and fuel performance for researchers [28].

In Australia, where this study is being conducted, most commuters drive an average of less than $50 \mathrm{~km}$ as a daily commute. As shown in Figure 5, in Sydney these commuters represent $64 \%$ of drivers and in Adelaide, $83 \%$. In many developing regions representative of our hypothetical markets, these figures are much higher. This is often

Page 4 of 7 because poor road conditions, severe congestion, and cost of transportation does not allow for practical long-distance daily commuting. In order to accurately model typical driving patterns, a comparative study was conducted utilising a $40 \mathrm{~km}$ distance travelled under both low and high-density drive cycles. The low and highdensity traffic patterns are developed from the standard drive cycles in order to capture the demands of the different traffic conditions, and are the result of analysis of a range of existing drive cycles and comparison against typical expected driving conditions.

The high-density drive cycle was developed using a combination of Urban Dynamometer Driving Schedule (UDDS), INDIAN URBAN and city-suburban heavy vehicle route (CSHVR) drive cycles in order to represent a typical daily trip on busy roads. The low-density drive cycle was been developed using the combination of New European Driving Cycle (NEDC), HWFET and INDIAN HIGHWAY drive cycles in order to represent a typical daily trip on busy roads. The objective of this analysis is to compare the fuel economy, emissions of the MHEV and a conventional powertrain for the authordeveloped low and high-density traffic patterns. The purpose of using cycles arranged in this method is to provide a more diverse set of driving conditions, where the driving cycles are not linked to a single method of development, reducing bias of the results to a particular drive cycle and developed in different traffic conditions.

Table 6 shows the characteristics of the author-developed cycles, which are weighted piecewise combinations of well-established and widely-accepted drive cycles. As with previous simulations, these author-developed cycles reinforce that traffic density is one of the main influences on fuel economy and emissions, which is not an unexpected result. The results consistently show that fuel economy of the MHEV is highly affected by the traffic, wherein a low density may yield worse fuel economy than a high one. This demonstrates the suitability of the MHEV topology described for urban environments. Other influencing factors include the chosen route and environmental effects including temperature and wind vector. The author-developed low- and high-density traffic drive cycles are shown in Figure 6 and Figure 7.

Table 6. The characteristics of low and high-density traffic patterns drive cycles.

\begin{tabular}{|c|c|c|}
\hline Density traffic patterns & High & Low \\
\hline Drive cycle & $\begin{array}{c}\text { UDDS + INDIAN } \\
\text { URBAN+ CSHVR }\end{array}$ & $\begin{array}{c}\text { NEDC + HWFET + } \\
\text { INDIAN } \\
\text { HIGHWAY }\end{array}$ \\
\hline Distance $(\mathrm{km})$ & 40 & 39.1 \\
\hline Time $(\mathrm{s})$ & 5840 & 2832 \\
\hline
\end{tabular}

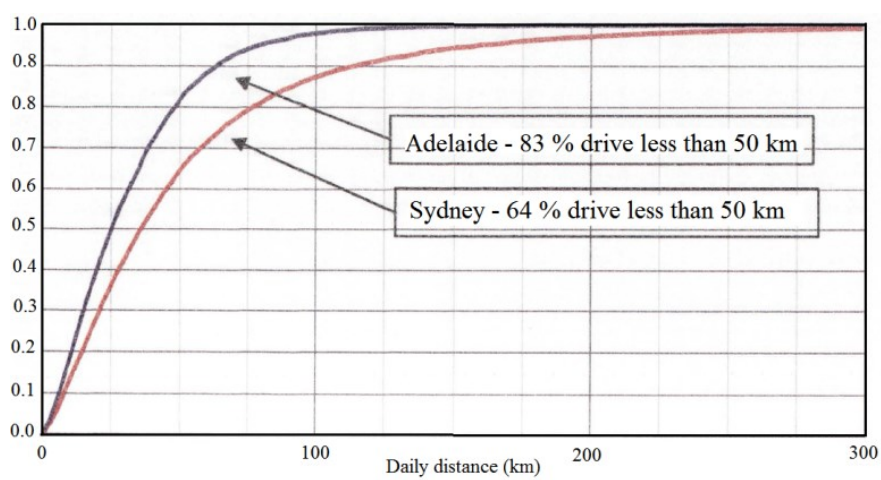

Figure 5. Cumulative distribution of daily driving distance in Australia [29]. 


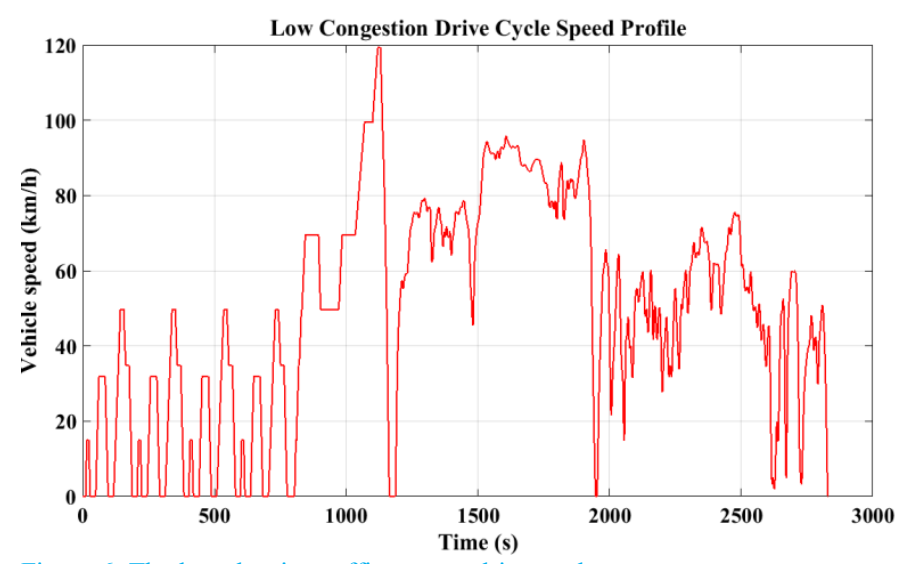

Figure 6. The low-density traffic pattern drive cycle.

Table 7. Fuel economy and emissions during the developed low and highdensity traffic patterns drive cycles.

\begin{tabular}{|c|c|c|c|c|c|}
\hline \multirow{2}{*}{} & \multicolumn{2}{|c|}{ MHEV } & \multicolumn{2}{c|}{ CV } \\
\cline { 3 - 6 } & Low & High & Low & High \\
\hline \multicolumn{2}{|c|}{ Fuel economy (L/100km) } & 5.8 & 8.5 & 6.5 & 11.1 \\
\hline \multirow{3}{*}{ Emissions (grams/km) } & HC & 0.19 & 0.23 & 0.22 & 0.27 \\
\cline { 2 - 6 } & $\mathrm{CO}$ & 0.56 & 0.62 & 0.61 & 1.2 \\
\cline { 2 - 6 } & NOx & 0.32 & 0.36 & 0.35 & 0.49 \\
\hline
\end{tabular}

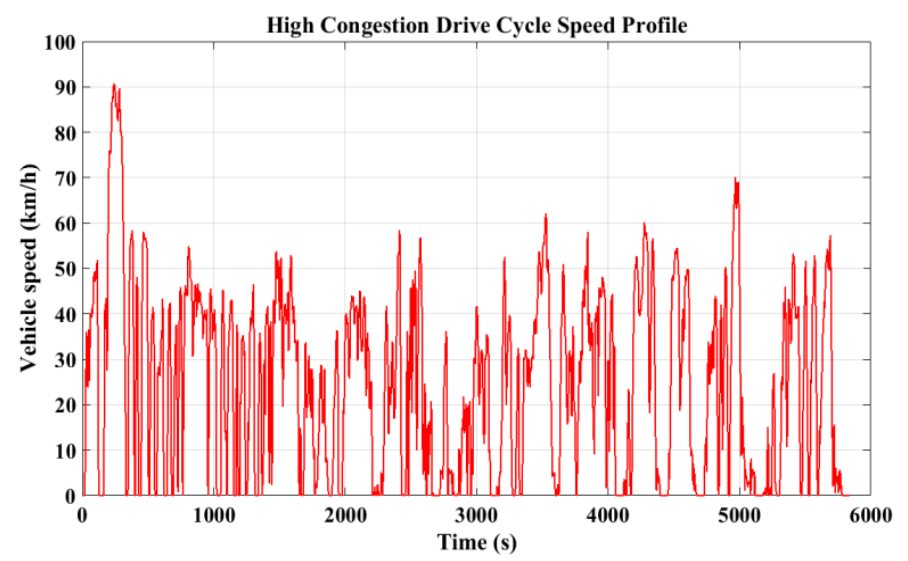

Figure 7. The high-density traffic pattern drive cycle.

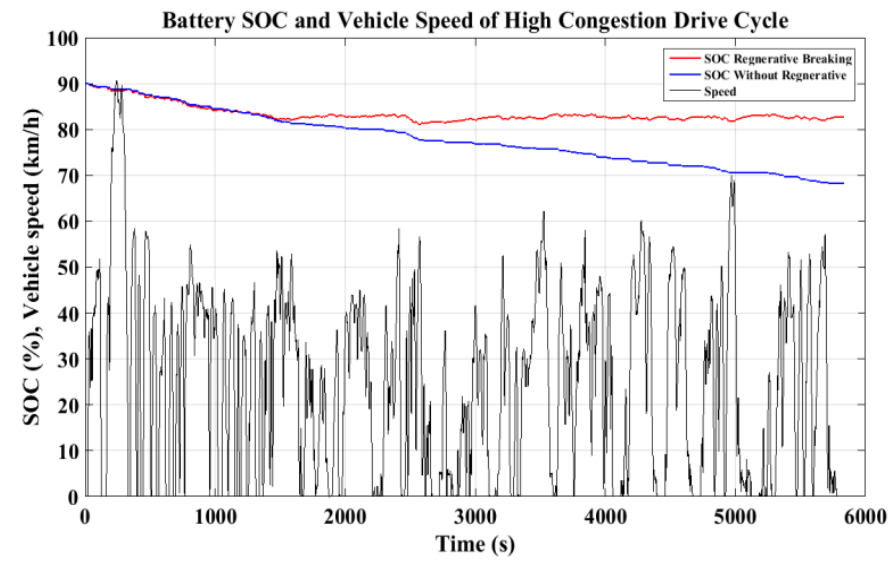

Figure 8. Battery SOC and Speed of High Congestion Drive Cycles.

Table 7 lists the vehicles fuel economy and emissions of the MHEV and a conventional vehicle (CV) during drive cycles featuring low Page 5 of 7 and high-density traffic patterns. The objective of this analysis is to determine the characteristics of each powertrain. As expected, the MHEV powertrain obtains higher fuel economy in high-density traffic compared to the CV under the same conditions. This is due to the higher proportion of time in traffic in which the electrified powertrain can be utilised either as motor or brake. Regenerative braking energy is captured during stop events in the high-density traffic pattern drive cycle and can be re-used for motive power under acceleration. However, based on the fuel economy analysis results, the low-density traffic combined with an aggressive driving style achieves lower fuel economy even with the MHEV powertrain. This is because more energy is required to repeatedly accelerate the vehicle, thereby lowering the utilisation factor of the electrified powertrain. A fuel improvement of approximately $23.5 \%$ is shown in high-density traffic and $10.7 \%$ in low-density traffic.

According to the simulation results, the MHEV powertrain has a significant improvement in the fuel economy and emissions for both driving styles compared to a conventional vehicle. This is because the MHEV powertrain provides somewhat improved load management for the internal combustion engine (ICE), but also recovers significant braking energy. The use of the electric machine to propel the vehicle during gear shifts results in disproportionate improvements in emissions performance - this is because the load factor during acceleration is much higher, and therefore any electric propulsion has significant emissions and fuel savings, thus reducing the harmful emissions from the ICE. At the same time, the MHEV powertrain also has the advantages of ultracapacitors, which can absorb significant regenerative braking energy and provide more peak power during hard acceleration. This technology is well-suited to the torque-filling function, which prioritises peak power over energy density.

\section{Discussion}

Improvement in comfort and driveability can be achieved through the reduction of torque-holes during gear shifts. This can be implemented by the use of a Mild Hybrid Vehicle (MHEV) powertrain, with minimal changes compared to a conventional vehicle with manual transmission. The traditional manual gearbox is the ideal platform for development and successful implementation of the torque-fill drivetrain, owing to its' simplicity and low cost. Values attained for both low and high traffic drive cycles fall within a predicted systemic pattern of behaviour. A realistic approach is taken in regards to sizing of the components of the vehicle subsystems, with the resultant performance output dictated by the desired benchmarking goals. The use of the MHEV as has been proposed is feasible and shows great potential. There is an observable improvement in the values yielded for GHG emissions and fuel economy for the drive cycles. The MHEV also achieves desired performance with a simpler architecture than many full-hybrid vehicles, which is essential in reducing cost. Therefore, implementation of the MHEV configuration is seen to be of great benefit.

In both the single drive cycle assessment and density traffic (drive cycles). Regardless of the type of drive cycle assessment used, the actual usage will generally comprise of a mixture of city and highway driving. However, the model does shine a light on the performance of mild hybrid powertrains to their application, in a way which is seldom presented to the consumer. The model potentially offers significant reductions in the fuel and emissions of GHGs, but is highly dependent on operating condition and may also produce very modest reductions if any. The important overriding finding is that emissions savings are seen under almost all conditions, and so the 
adoption of MHEV must be considered a positive step for the environment. The investment will actually realise significant savings in running costs, as well as significant environmental benefits.

\section{Conclusion}

Based on the fuel economy and emissions comparison for the tests during the INDIAN URBAN, HWFET and combined drive cycles, the MHEV powertrain fuel economy is improved, and the emissions are reduced significantly compared to the conventional vehicle. The fuel economy and emissions also depend on the driver's behaviour when handling the vehicles and traffic density of a drive cycle. Comparing the simulation results, the MHEV powertrain uses less fuel energy, which has improved the fuel economy, emissions and electrical consumption.

The implementation of the system was underpinned by a low-tech $\mathrm{B} / \mathrm{C}$-segment passenger car. This was selected for two reasons; these vehicles are generally very common in most regions, developing or otherwise. Also, such a common vehicle will allow future development, including laboratory testing, to continue using a readily available vehicle that matches well with physical characteristics used in simulations. Benefits of the system were shown to be generally favourable in software, showing improvement in fuel economy.

Further development of the system may realise an anti-jerk control in addition to the torque hole fill-in. This could be executed using the same electric machine, yielding further driveability improvement. With an AMT instead of a traditional manual, the system could operate completely automatically without driver intervention. Finally, since the model utilised in the MATLAB and Simulink model is based on a simple calculation, it is recommended that further work be performed to increase the accuracy of the model.

\section{References}

[1] Sharma, R., Bessede, M., Manzie, C., Brear, M., and Crawford, R., "An Economic and In-Service Emissions Analysis of Conventional, Hybrid and Electric Vehicles for Australian Driving Conditions," SAE International Journal of Commercial Vehicles 5(1):291-298, 2012, doi: 10.4271/2012-01-0819.

[2] Liu, Z., Ivanco, A., and Filipi, Z. S., "Impacts of RealWorld Driving and Driver Aggressiveness on Fuel Consumption of 48V Mild Hybrid Vehicle," SAE International Journal of Alternative Powertrains 5(2):249258, 2016, doi: 10.4271/2016-01-1166.

[3] Zhang, X., Li, C.-T., Kum, D., and Peng, H., "Prius+ and Volt-: Configuration Analysis of Power-Split Hybrid Vehicles With a Single Planetary Gear," IEEE Transactions on Vehicular Technology 61(8):3544-3552, 2012, doi: 10.1109/TVT.2012.2208210.

[4] Wagner, U. and Wagner, A., "Electrical Shift Gearbox (ESG) - Consistent Development of the Dual Clutch Transmission to a Mild Hybrid System," 2005, doi: 10.4271/2005-01-4182.

[5] Wu, G. and Wu, H., "Vibro-Impact Analysis of Manual Transmission Gear Rattle and Its Sound Quality Evaluation," 2017, doi: 10.4271/2017-01-0403.

[6] Hawkins, S., Billotto, F., Cottrell, D., Houtman, A., Poulos, S., Rademacher, R., Van Maanen, K., and Wilson, D., "Development of General Motors' eAssist Powertrain,"
SAE International Journal of Alternative Powertrains 1(1):308-323, 2012, doi: 10.4271/2012-01-1039.

\section{Baraszu, R. C. and Cikanek, S. R., "Torque fill-in for an} automated shift manual transmission in a parallel hybrid electric vehicle," Proceedings of the 2002 American Control Conference (IEEE Cat. No.CH37301), 8-10 May 2002, 2002, doi: 10.1109/ACC.2002.1023222.

[8] Ehsani, M., Gao, Y., and Emadi, A., "Fundamentals of Vehicle Propulsion and Brake," in Modern electric, hybrid electric, and fuel cell vehicles: fundamentals, theory, and design, (CRC press, 2009), doi: 10.1201/9781420037739.

[9] Galvagno, E., Velardocchia, M., and Vigliani, A., "Analysis and simulation of a torque assist automated manual transmission," Mechanical Systems and Signal Processing 25(6):1877-1886, 2011, doi: 10.1016/j.ymssp.2010.12.014

[10] Gao, B., Liang, Q., Xiang, Y., Guo, L., and Chen, H., "Gear ratio optimization and shift control of 2-speed IAMT in electric vehicle," Mechanical Systems and Signal Processing 50(615-631, 2015, doi:

10.1016/j.ymssp.2014.05.045.

[11] Liu, H., Lei, Y., Li, Z., Zhang, J., and Li, Y., "Gear-Shift Strategy for a Clutchless Automated Manual Transmission in Battery Electric Vehicles," SAE International Journal of Commercial Vehicles 5(1):57-62, 2012, doi: 10.4271/201201-0115.

[12] Sorniotti, A., Holdstock, T., Everitt, M., Fracchia, M., Viotto, F., Cavallino, C., and Bertolotto, S., "A novel clutchless multiple-speed transmission for electric axles," International Journal of Powertrains 2(2-3):103-131, 2013, doi: 10.1504/IJPT.2013.054155.

[13] Awadallah, M., Tawadros, P., Walker, P., and Zhang, N., "Dynamic modelling and simulation of a manual transmission based mild hybrid vehicle," Mechanism and Machine Theory 112(218-239, 2017, doi: 10.1016/j.mechmachtheory.2017.02.011.

[14] Awadallah, M., Tawadros, P., Walker, P., and Zhang, N., "Eliminating the torque hole: Using a mild hybrid EV architecture to deliver better driveability," 2016 IEEE Transportation Electrification Conference and Expo, AsiaPacific (ITEC Asia-Pacific), Busan, South Korea, June 1-4, 2016, 2016, doi: 10.1109/ITEC-AP.2016.7512943.

[15] Awadallah, M., Tawadros, P., Walker, P., and Zhang, N., "Comparative System Dynamic Modeling of a Conventional and Hybrid Electric Powertrain," in Power Engineering - International conference on Power Transmissions (ICPT 2016), Y. S. Datong Qin, (Chongqing, China, CRC Press, 2016), 231-238, doi: 10.1201/9781315386829-36.

[16] Awadallah, M., Tawadros, P., Walker, P., and Zhang, N., "A System Analysis and Modeling of a HEV based on Ultracapacitor Battery," 2017 IEEE Transportation Electrification Conference and Expo (ITEC), Chicago, Illinois, USA, June 22-24, 2017, 2017.

[17] Hutchinson, T., Burgess, S., and Herrmann, G., "Current hybrid-electric powertrain architectures: Applying empirical design data to life cycle assessment and wholelife cost analysis," Applied Energy 119(314-329, 2014

[18] Liu, Z., Ortmann, W. J., Nefcy, B., Colvin, D., and Connolly, F., "Methods of Measuring Regenerative Braking Efficiency in a Test Cycle," SAE International Journal of Alternative Powertrains 6(1):103-112, 2017, doi: 10.4271/2017-01-1168.

[19] Sun, L. and Zhang, N., "Design, implementation and characterization of a novel bi-directional energy conversion

Page 6 of 7 
system on DC motor drive using super-capacitors," Applied Energy 153(101-111, 2015.

[20] Sun, L., Awadallah, M., Chi, L., and Zhang, N., "An Electric Scooter with Super-Capacitor Drive and Regenerative Braking," SAE 2014 World Congress \& Exhibition, Detroit, Michigan, USA, 2014-04-01, 2014, doi: 10.4271/2014-01-1878.

[21] Honey, E. and Suh, I.-S., "A feasibility study of an electric-hydraulic hybrid powertrain for passenger vehicles," Proceedings of the Institution of Mechanical Engineers, Part D: Journal of Automobile Engineering 229(14):1894-1906, 2015.

[22] Awadallah, M., Tawadros, P., Walker, P., and Zhang, N., "A Low-Cost and Novel Approach in Gearshift Control for a Mild-Hybrid Powertrain," 2017 IEEE Transportation Electrification Conference and Expo (ITEC), Chicago, Illinois, USA, June 22-24, 2017, 2017.

[23] Tawadros, P. and Zhang, N., "Quantitative Experimental Study of HEV Regenerative Braking Systems," Eurobrake 2012, Dresden, Germany, June 22-24, 2017, 2012.

[24] Awadallah, M., Tawadros, P., Walker, P., and Zhang, N., "A Comparative Fuel Analysis of a novel HEV with conventional vehicle," Vehicular Technology Conference (VTC Spring), 2017 IEEE 85th, Sydney, Australia, June 47, 2017, 2017.

[25] Wei, Z., Xu, J., and Halim, D., "HEV power management control strategy for urban driving," Applied Energy, 2016.

[26] Ruan, J., Walker, P., Zhang, N., and Xu, G., "The Safety and Dynamic Performance of Blended Brake System on a Two-Speed DCT Based Battery Electric Vehicle," $S A E$ International Journal of Passenger Cars - Mechanical Systems 9(1):143-153, 2016, doi: 10.4271/2016-01-0468.

[27] Salisa, A. R., Zhang, N., and Zhu, J., "A comparative analysis of fuel economy and emissions between a conventional HEV and the UTS PHEV," IEEE

Transactions on Vehicular Technology 60(1):44-54, 2011, doi: 10.1109/TVT.2010.2091156.

[28] Rubino, L., Bonnel, P., Carriero, M., and Krasenbrink, A., "Portable Emission Measurement System (PEMS) For Heavy Duty Diesel Vehicle PM Measurement: The European PM PEMS Program," SAE International Journal of Engines 2(2):660-673, 2009, doi: 10.4271/2009-240149 .
Abdul Rahman, S., "Optimal power management for the UTS plug-in hybrid electric vehicle," University of Technology Sydney, Australia, 2011.

\section{Contact Information}

Contact information of the main author is as follows:

Faculty of Engineering and IT, University of Technology Sydney, in the school of Electrical, Mechanical and Mechatronic Systems.

15 Broadway, Ultimo, NSW, Australia 2007.

Mohamed.M.Awadallah@student.uts.edu.au

Eng.m.zakaria@gmail.com

Phone: +61-470600971

\section{Acknowledgments}

The financial support of this work by the Australian Research Council (DP150102751), Excellerate Australia (1-204) and the University of Technology Sydney, is gratefully acknowledged. We also wish to express our sincere gratitude to our research supervisor, Prof. Nong Zhang, and our thanks to the UTS - Green Energy Vehicle Innovations (GEVI) team.

\section{Definitions/Abbreviations}

$\begin{array}{ll}\text { ICE } & \text { Internal Combustion Engine } \\ \text { CV } & \text { Conventional Vehicle } \\ \text { MHEV } & \text { Mild Hybrid Electric Vehicle } \\ \text { BLDC } & \text { Brushless DC Motor } \\ \text { MT } & \text { Manual Transmission } \\ \text { EM } & \text { Electric Machine } \\ \text { DCT } & \text { Dual-Clutch Transmission } \\ \text { AMT } & \text { Automated manual transmission } \\ \text { CVT } & \text { Continuously Variable Transmission } \\ \text { GHG } & \text { Greenhouse Gas Emissions } \\ \text { SOC } & \text { State of Charge } \\ \text { DOF } & \text { Degree-of-Freedom } \\ \text { CO } & \text { Carbon Monoxide } \\ \text { HC } & \text { Hydrocarbons } \\ \text { NOx } & \text { Oxides of Nitrogen } \\ \text { PM } & \text { Particulate Matter }\end{array}$

